\title{
O lead nos títulos jornalísticos: um estudo comparado entre os jornais Folha de S. Paulo e O Estado de S.Paulo
}

\section{The lead in journalistic headlines: a comparative study between the newspaper Folha de S. Paulo and O Estado de S.Paulo}

\author{
Lucas Santiago Arraes Reino ${ }^{1}$, Thaísa Cristina Bueno ${ }^{2}$
}

Professor adjunto do curso de Jornalismo da Universidade Federal do Maranhão (UFMA), doutor em Comunicação pela Pontifícia Universidade Católica do Rio Grande do Sul (PUC-RS), mestre em Ciência da informação pela Universidade de Brasília (UnB), especialista em Comunicação Empresarial pela Universidade para o Desenvolvimento do Estado e da Região do Pantanal (Uniderp) e graduado em Jornalismo pela Universidade Federal do Mato Grosso do Sul (UFMS). E-mail: lucas@ufma.br. 


\section{Resumo}

Trabalhados de formas diferentes para as capas dos jornais impressos e para a internet, os títulos possuem uma íntima ligação com o lead, já que resumem a informação do primeiro parágrafo em um número menor de palavras. Nesse sentido, este artigo recupera de forma breve a história do chamado título informativo e discute sua relação com o lead. A proposta é entender quais perguntas que compõem o lead são costumeiramente destacadas nos títulos e se há diferenças nessa seleção quando o título está na plataforma digital ou de papel. O estudo tem como base um levantamento feito nos jornais Folha de S.Paulo e $O$ Estado de S.Paulo, no meio impresso e na Internet. Ao todo, 206 títulos foram analisados. Por fim, coloca-se a prova o que é e o que deixou de ser característica do título jornalístico.

Palavras-chave

Título, lead, jornalismo.

\section{Abstract}

Designed for the covers of print and online newspapers in different ways, the headlines have an intimate connection with the lead, since they summarize the first paragraph's information in fewer words. In this sense, this article reviews briefly the history of the so called informational headline and discusses its relation with the lead. The purpose is to understand which questions that make up the lead are customarily highlighted in the headlines and if there are differences in this selection when the headline is on a digital platform or paper. The study is based on a survey done on newspapers Folha de S.Paulo and O Estado de S.Paulo, print and online. Altogether, 206 headlines were analyzed. Finally, it has been tested what is and what is no longer a feature of the journalistic headline.

\section{Keywords}

Headline, lead, journalism. 
Os títulos das matérias jornalísticas são, se não o mais importante, provavelmente o primeiro critério de seleção que o leitor usa para decidir se continua ou abandona a leitura do texto. A metáfora de que os títulos seriam como "lanternas" para guiar o leitor parece exemplificar bem a proposta dessa estratégia de edição. "Antes de ir ao texto principal, o olho passeia pelos títulos [...] à procura de saber do que se trata a reportagem, à procura de uma lanterna". Mas, substancialmente, como defendem, "bons títulos economizam o tempo do leitor" (ASSUMPÇÃO; BOCHINI, 2006, p. 16-17).

Nesse sentido, à luz de Mouillaud (2002, p. 77), "se podemos dizer que o acontecimento tem um lugar privilegiado, é a região dos títulos". E mais, ratifica Burnett (1991, p. 43): "sem um título atraente o leitor não chega sequer ao lead". Não é à toa que ocupa, por desempenhar um papel de tamanha responsabilidade, também um espaço de realce, seja num lugar privilegiado na disposição gráfica dos jornais ou sites, ou, pelo menos, em evidência com relação ao restante das matérias.

\footnotetext{
Mais importante que o lead, do ponto de vista do consumidor, só o título. Sem um título atraente o leitor não chega sequer ao lead. A notícia, como os homens, vale pelos títulos. Daí a necessidade de saber montar o lead exato, de modo a permitir o título atraente (BURNETT, 1976, p. 37).
}

E se é um ponto primordial na matéria, pelo menos quando se pensa no jornalismo moderno, posterior à profissionalização dos anos 1950, parecem ser consenso a importância e o papel desses textos curtos. Diversos autores, como Amaral (1986, p. 57) - "anunciar a notícia, de forma clara, objetiva e atraente" -, Bahia (1974, p. 160) - extrair do texto toda a sua essência, interesse, objetividade, atualidade, novidade; transmitir o impacto da notícia; reunir concisamente o conteúdo da notícia; informar, sintetizando e valorizando a notícia -, Douglas (1966, p. 27) - "anunciar a notícia, resumir seu conteúdo, indicar a importância relativa da informação e conferir aspecto atraente a página do jornal" -, entre outros, parecem compartilhar deste entendimento: títulos informativos devem adotar uma linguagem clara e objetiva; precisam, sempre, resumir em poucas palavras o assunto a ser tratado na notícia e serem escritos 
de forma atraente para fisgar a atenção do leitor diante da oferta de notícias cada vez maior.

Além disso, como esclarece Guimarães (1995, p. 51), os títulos "não são meros artifícios publicitários, mas chaves para a decodificação da mensagem, se convenientemente propostos". A autora argumenta, inclusive, que o título constrói significados antecipados do sentido da matéria. Ou seja, ratifica a ideia de que, para além de um recurso técnico (forma e tamanho), é um argumento semântico que integra a orientação editorial dos veículos. Ao elencar as funções do título, Gradim (2000, p. 70) aponta, entre outras, as funções de "informar" e de "despertar atenção", mais uma vez reafirmando o seu papel informativo e sensorial na produção jornalística.

O assunto é tão coberto de pormenores que Medina (2001b), numa tentativa de atualização da classificação tradicional de gêneros jornalísticos do pesquisador Marques de Melo (2010), incluiu o título como um subgênero do modelo informativo.

A inclusão dos títulos [...] como subgênero dos gêneros informativos [...] foi devido a sua grande importância no jornalismo. Os títulos falam por si mesmo, despertando o interesse do público para as matérias jornalísticas. Como sabemos, a maioria dos leitores se limita somente a leitura de títulos e são os títulos que vão motivar a lerem ou não as notícias contidas nos jornais. [...] Os títulos de primeira página destacam as notícias que foram consideradas, pela empresa jornalística, como as mais importantes, como as mais ricas em emoções para os seus leitores" (MEDINA, 2001b, p. 48).

E Medina (2001a) destaca que pensar no título implica estudar o texto em pelo menos dois aspectos: um semântico, já que este representa uma construção de significados que compõem a história narrada, reafirmando uma peculiaridade apontada pelos autores supracitados; e outro estético, já que há uma organização e uma forma que demarcam o espaço do título enquanto parte da narrativa jornalística. "Os títulos de imprensa recorrem [...] tanto à plasticidade verbal como à plasticidade gráfica. É, aliás, através do grafismo que a retórica discursiva se abre a recursos semióticos extralinguísticos, com particular relevo para a imagética" (MEDINA, 2001a, p. 49). 
A partir de tais ponderações, juntamente com os argumentos dos demais autores citados, tentamos esclarecer que, embora neste artigo abordemos a construção do título enfatizando seus aspectos estruturais (substancialmente as escolhas das perguntas-guias do lead, além de tempos e formas verbais e de número de palavras), entendemos que tais seleções não estão dissociadas da construção semântica e editorial dos veículos, com muito bem elucidam autores como Guimarães (1995), Garcia (2005) e Gradim (2000). No entanto, partimos da premissa de que, mesmo que tal marca não invalide a outra, enxergar a estrutura dos títulos é um passo importante na pesquisa do título, já que boa parte dessas orientações mais distintas são as mais apresentadas nos verbetes dos manuais dos veículos, sejam os especificamente estudados no artigo ou outros, como $O$ Globo (2005) e o Diário Carioca (1950).

Além disso, este estudo, no formato proposto, pode servir de base para disciplinas práticas de edição ou para enxergar o modelo da redação na internet.

E aproximando toda essa discussão da proposta deste artigo, vale uma conversa bastante esclarecedora com Douglas (1966, p. 16, grifos do autor), para quem há necessidade de o título dialogar diretamente com o lead da matéria. 0 autor chega a cunhar a expressão "superlead" para descrever essa característica.

Enquanto o lead fala por meio de orações e períodos, livremente organizados, o título expressa-se com limitado número de palavras acuradamente escolhidas para delas se extrair o máximo efeito. Neste sentido o título é, portanto, um superlead, a condensação do lead.

E se, conforme pontuam os autores, os leads são um guia do título, por serem mais curtos que o primeiro parágrafo, não podem, no entanto, contemplar todas as seis perguntas do lead (quem, o quê, quando, como, onde e por quê?). Sabendo disso, a proposta deste artigo é justamente entender os títulos do jornalismo contemporâneo, tentando identificar quais perguntas do lead são mais usadas nos títulos. Além das tradicionais seis perguntas que guiam o primeiro parágrafo das matérias jornalísticas no padrão norte-americano, iniciado nos Estados Unidos no final do século XIX e introduzido no Brasil em 1950, nesta 
investigação acrescentamos mais uma pergunta: "quantos?". A estratégia, embora não integre o lead tradicional, não inviabiliza a pergunta-guia do artigo, mas a complementa, e foi acrescida porque acreditamos que os números, mesmo que não tenham se configurado na normatização do primeiro parágrafo, são comumente usados nas construções textuais das notícias e, portanto, podem estar sendo adotados com frequência no espaço importante do título.

Para ampliar a discussão sobre as particularidades dos títulos no jornalismo atual, algumas orientações que configuram, geralmente, guias de produção jornalística também foram investigadas, tendo como base os textos sobre título dos manuais de dois jornais selecionados. O levantamento descritivo contempla a análise de uma semana das publicações impressas (capa e página interna) e on-line (capa do site e página interna) de dois dos jornais mais admirados do país, conforme a pesquisa Meio \& Mensagem do Grupo Troiano Branding, que tem mais de dez anos no país e em 2016 ouviu 809 pessoas, entre profissionais de agências de publicidade, executivos de grandes anunciantes e empresas de marketing. No levantamento daquele ano sobre o Índice de Prestígio de Marca (IPM) a Folha de S.Paulo e O Estado de S.Paulo ficaram empatados como os dois jornais mais admirados.

A análise dos títulos inclui os publicados entre os dias 1 e 7 de abril, uma semana comum, sem grandes acontecimentos, para dar conta de relatar algo ordinário na prática do jornal. Os títulos selecionados foram retirados das editorias tradicionais dos veículos cujos temas estavam contemplados em ambos: Capa (manchete), Política, Cultura, Esporte e Economia. Ao todo foram estudados 204 títulos.

\section{Túnel do tempo: uma breve história dos títulos}

Como diz Camasseto (2001, p. 39), "se, para o jornalista, é no lead que a construção da notícia começa, uma vez que é dali que sai o título, com o leitor é diferente. É justamente no título que a sua participação se inicia". O fato é que nem sempre os títulos tiveram a importância e o espaço distintos, tal qual entendemos hoje como uma titulação tradicional. 
De acordo com Marques de Melo (1985), até o século XIX, nos Estados Unidos, e o começo do século passado no Brasil, os títulos funcionavam como meros indicadores de assunto, ou seja, apenas uma palavra ou duas em destaque. Esse ator coadjuvante, como descreve o autor, aparecia para o leitor como "rubricas", que garantiam pouquíssima distinção temática entre um texto e outro. A descrição é ratificada por Douglas (1966, p. 17), quando lembra que "antes da segunda metade do século XIX, os títulos eram simples rótulos, com declaração genérica e indefinida, pouca ou nenhuma informação sobre a notícia". Esses títulos-rótulo eram usualmente impressos em tipos não muito maiores do que os do texto da matéria. Se, como lembra Satori (1999), até o fim do século XIX os títulos não passavam de "fórmulas para separar diferentes tipos de texto", e com a profissionalização das redações passaram a ganhar uma função mais expressiva e estética.

Melo (1985) lembra que nesse momento é que se populariza o que chama de "títulos-notícia". Diferentes dos anteriores, apenas temáticos, esses são o reflexo da mercantilização do conhecimento, o chamariz de venda, quase uma peça publicitária. No Brasil, entre os nomes visionários que representam essa mudança está a figura de Pompeu de Sousa, que na reformulação do Diário Carioca (fim de 1950) é responsável por uma orientação de edição que o jornalismo carrega até hoje.

\section{Manuais de redação e o verbete sobre títulos}

Tanto a Folha de S.Paulo quanto O Estado de S.Paulo possuem manuais com o verbete "título". Orientações sobre o fazer do título aparecem já no primeiro manual de redação do jornal Diário Carioca, embora nele sejam encontradas no tópico "Cabeças". Os três tratam mais claramente da estrutura que das escolhas editoriais ou semânticas. A Folha de S.Paulo, por exemplo, traz informações como: não use ponto, nem dois pontos, evite ponto vírgula, não divida as palavras, use o espaço total, não repita a mesma palavra do lead. Até o fim do texto nada sobre ser criativo ou informativo, apenas em uma página do veículo na internet aparece a seguinte orientação: "O título deve ser uma síntese precisa 
da informação mais importante do texto. Sempre deve procurar o aspecto mais específico do assunto, não o mais geral" (TÍTULO, 1996).

Inclusive, a página lista títulos que considera adequados e inadequados. Ao todo posta dez exemplos de cada (TÍTULO, 1996). Dos corretos, sete começam com a resposta à pergunta "quem" e um à pergunta "quantos" ("60\% querem pena de morte no país"). Nos contraexemplos, estão títulos iniciados com verbo ("Começa hoje o Festival de Cannes"), entre outros exemplos que não se adequam à orientação estrutural do manual.

O manual do Estadão traz 14 tópicos sobre títulos, entre eles a orientação para que sejam curtos, que tenham verbos e, no quarto tópico, que "deverá obrigatoriamente ser extraído do lead; se isso não for possível, refaça o lead" (MARTINS FILHO, 1997, p. 282). Também trata de rigores quanto ao limite de sinais.

\section{Título e lead: uma relação de parentesco}

Se o título deixou de ser um rótulo para as notícias e começou a ser um título-informativo, como explica Douglas (1966, p. 16), novas exigências surgiram para os editores e repórteres dos jornais impressos. Entre elas, o autor destaca duas que considera essenciais para o título: "deve ser bem contado e deve resumir precisamente a notícia". Ser bem contado é estar escrito adequadamente para o espaço do jornal, sua quantidade de caracteres, sua gramática correta etc. Já da parte de resumir precisamente a notícia, fica a cargo de quem fez o título ter a capacidade de resumir em poucas palavras o que diz de mais importante o texto, ou seja, o que está mais detalhadamente explicitado no lead. Sem querer entrar no debate de alternativas à pirâmide invertida, até mesmo críticos do modelo "como a função da notícia é basicamente relatar um fato (e, sendo normalmente mais curta, sem detalhar demais as informações, fica difícil tirá-la dos padrões da pirâmide inversa e do lead" (AMEDEI, 2007, p. 24) - entendem que, na notícia, a estruturação que começou em 1050 no país ainda é usual e atende a demandas de urgência, pelo menos no texto noticioso. Obviamente que não ignoramos alternativas ao lead, particularmente nas reportagens, mas como neste artigo 
basicamente estudamos jornalismo diário e notícias, a proposta de aproximar título e lead se justifica. Além disso, sua adoção é explicitamente orientada nos dois manuais dos veículos estudados.

Na Folha de S.Paulo, ao defender o lead em reportagens, inclusive, o jornal escreve: "pressupõe que qualquer texto publicado no jornal disponha de um núcleo de interesse [...] imprescindível à valorização da reportagem e útil à dinâmica da leitura contemporânea" (2002, p. 28, grifos do autor); já o Estadão coloca como indispensável a opção pelo lead na "abertura da matéria" (MARTINS FILHO, 1997, p. 154). Assim, sabendo que o texto deve começar pelo que é considerado mais relevante para o veículo, entende-se que o título deve estar ligado diretamente ao lead, já que ele sintetiza o que é mais urgente e pulsante do ponto de vista dos critérios de noticiabilidade e de gancho nas matérias publicadas nos jornais. Ao tratar do gancho nas produções da imprensa, Bueno e Reino (2012, p. 1) ponderam que essa é "provavelmente, a característica mais marcante do texto jornalístico que vai transformar o ato de contar uma história numa narrativa jornalística e não em um texto qualquer". Comassetto (2003, p. 29) reforça essa explicação: "o lead corresponde ao primeiro parágrafo da notícia, onde devem constar as informações mais importantes, na concepção do redator e no suposto interesse dos leitores".

O lead é a abertura da matéria. Nos textos noticiosos, deve incluir, em duas ou três frases, as informações essenciais que transmitam ao leitor um resumo completo do fato. Precisa sempre responder às questões fundamentais do jornalismo: o quê, quem, quando, onde, como e por quê (MARTINS FILHO, 1997, p. 42, grifos do autor).

A proposta de que o título seja essa síntese do lead veio da percepção dos editores Joseph Pulitzer, do New York World, e Randolph Hearst, do New York Journal. Douglas (1966) relata que ambos perceberam que para vencer a disputa comercial em que estavam ia ser preciso desenvolver o aspecto tipográfico, fazendo, entre outras coisas, uma ampliação do título na capa do jornal. Com isso, o título começou a ganhar importância e a assumir novas funções no jornal, e tornou-se 
necessário fazer a conexão entre ele o primeiro parágrafo. Comassetto (2003, p. 42-43) lembra que a limitação espacial do título é sanada pelo lead, por isso também há grande relevância dessa conexão entre ambos:

\begin{abstract}
É importante deixar claro que, apesar de sua capacidade informativa, o título não consegue cobrir toda informação do texto. Ele contempla apenas parte dela, expressando, de preferência, a principal macroproposição. Outras informações importantes terão que ser buscadas no lead, que, junto com o título, deve expressar a macroestrutura semântica da matéria. Juntas, as duas categorias funcionam como sumarização do texto, presidindo a organização e distribuição de circunstâncias e informações secundárias (Ibid., 2013, p. 42-43).
\end{abstract}

Explicitando ou não, por tudo isso entende-se que o título deve estar ligado diretamente ao lead. Logo, o título, sendo uma síntese do lead, deve contemplar parte dos questionamentos que guiam sua tessitura.

Para o jornalista, é no lead que a construção da notícia começa, uma vez que é dali que sai o título, com o leitor é diferente. É justamente no título que a sua participação se inicia, pois, de acordo com nossa cultura jornalística, é o título (ou manchete) que encabeça a notícia em veículos impressos (Ibid., 2001, p. 39).

Portanto, em uma notícia ordinária ou numa reportagem aprofundada, dos questionamentos que guiam a produção jornalística (referimo-nos às perguntas do lead) algo é tomado como o mais importante e será privilegiado no título. A teoria do Newsmaking trabalha detidamente esse tema, discutindo o que tem mais relevância entre o que é noticiado e, consequentemente, o que se torna o gancho da notícia, indo para o destaque no título. Desse modo, a partir do que foi exposto, a pergunta que guia este estudo é: quais das perguntas utilizadas no lead são mais usuais na construção do título?

\title{
Um novo "q" para o lead
}

A inclusão de mais um " $q$ " na pesquisa é para averiguar se "quantos" tem sido usada nos títulos na mesma proporção que as demais perguntas do lead. 
Por quê? Primeiro, é uma hipótese dos pesquisadores que os números sejam um chamariz que é adotado pelos jornais já nas primeiras páginas; segundo, porque acreditamos que dados e estatísticas enriquecem o texto e têm recebido mais destaque particularmente com o advento das pesquisas de dados no ciberespaço.

$\mathrm{Na}$ internet, cada dia mais os jornais precisam lidar com bases de dados e isso pode ser um indício de que os números podem também estar indo para os títulos. Como está escrito também no Manual de Jornalismo de Dados (2015), "para atrair leitores com jornalismo de dados, você tem de conseguir mostrar algum número na manchete que os faça sentar e prestar atenção".

\section{Os títulos hoje: estudo dos jornais Folha de S.Paulo e O Estado de S.Paulo}

Este estudo tem como objeto de análise os títulos publicados durante uma semana (de 1 a 7 de abril de 2016) nos jornais Folha de S.Paulo e O Estado de S. Paulo. A proposta é descrever os títulos publicados nas capas de cada um dos veículos e seus correspondentes na página interna do periódico impresso, bem como os títulos das mesmas matérias na página inicial do site do veículo e seu correlato na página da matéria. Além da manchete, o estudo inclui os títulos das editorias Cultura, Política, Esporte e Economia. Estas foram escolhidas por serem comuns aos dois jornais.

O levantamento busca descrever os títulos na sua estrutura, mais especificamente no número de palavras usadas, para conhecer efetivamente o tamanho dos títulos e se há diferenciações de tamanhos entre os títulos da capa e da parte interna, e entre o modelo adotado no formato impresso e no on-line.

Além disso, busca-se saber quais perguntas do lead são mais usadas nos títulos, além de confirmar, com precisão, qual delas é mais usada como a primeira palavra do título. Isso mostra o que o jornal prioriza. Além das perguntas clássicas, incluímos, também, a palavra "quantos", já que é praxe no jornalismo dizer que os números costumam ser destaque nas produções noticiosas.

Queremos, com isso, olhar para o lead, na atual conjuntura de discussões acerca de novas possibilidades, e verificar quais são as perguntas mais usadas e 
como são usadas. Além de trazer um novo fôlego para o assunto, pretendemos contribuir para estudos dos títulos, cujas pesquisas, na sua grande maioria, tratam de sua função semântica e informativa, mas pouco de suas regras estruturais. Substancialmente, esta é uma pesquisa de averiguação, para confirmar ou desmitificar parte das regras de redação, buscando um diálogo entre campo, autores e manuais.

Sobre as perguntas do lead que aparecem no título, em média, duas ou três delas acabam formando a frase de abertura do texto noticioso. Pelo resultado encontrado, "o quê" e "quem" são efetivamente as perguntas mais importantes que guiam os editores na construção do título. 92,6\% dos títulos analisados, ou seja, 189 de um total de 200, responderam à pergunta "o quê"; seguida de "quem", o sujeito da ação, em 84,3\%. A terceira pergunta mais utilizada não faz parte da listagem tradicional do lead, que foi "quantos".

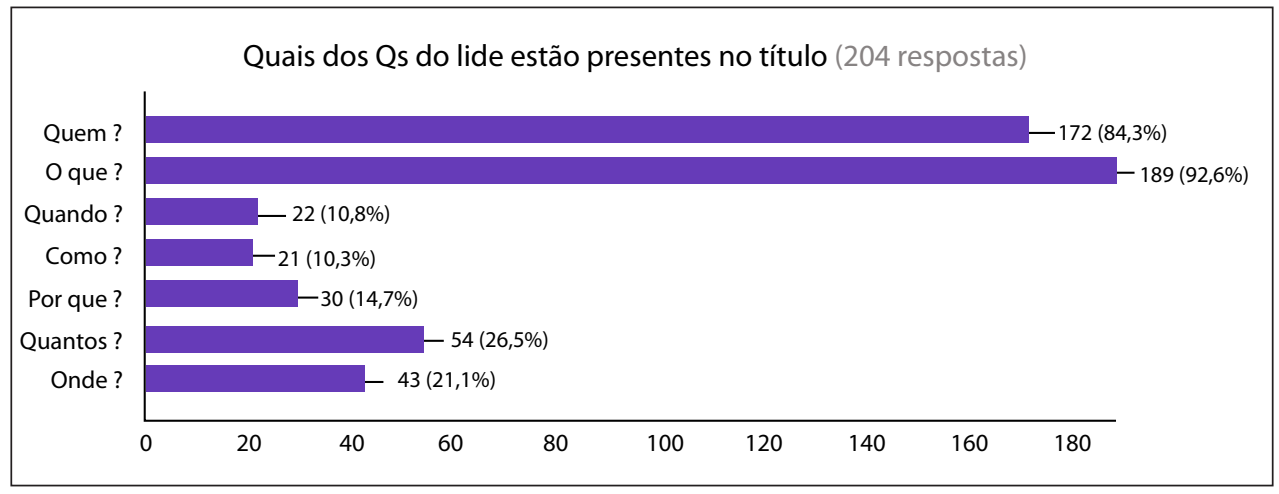

Gráfico 1: Quais perguntas do lead aparecem nos títulos?

Fonte: Elaborado pelos autores (2016)

A resposta apresentada no Gráfico 1 aponta duas coisas bem importantes, que ratificam a ideia de que os fatos não podem ser suplantados em nome de sugestões ou surpresas. Não podem ser "escondidos", mas sim explicitados no título. O sujeito também apareceu bastante, embora nem sempre seja uma celebridade, podendo ser uma instituição, um grupo ou algo do gênero. Já a pergunta "quantos" aparece em terceiro lugar, uma frequência muito significativa, que aponta para um possível acerto da hipótese de pesquisa e que justifica sua 
inclusão. Nos títulos analisados, os números estão não apenas na editoria de Economia, mas nas editorias de Geral e de Esporte são bem comuns também. Pelo que mostram, os números são um método mais importante de seleção para os títulos que os quatro outros critérios do lead tradicional.

Se "o quê" e "quem" efetivamente são as perguntas que mais aparecem nos títulos, é o sujeito da ação que costumeiramente é utilizado para dar início à frase que compõe o título. Dos 200 títulos publicados no período de análise, $53 \%$ começam com "quem", quase o dobro de vezes que o segundo colocado, "o quê", que começa o título $27 \%$ das vezes. O resultado surpreende, já que, via de regra, costuma-se pensar que o fato, "o quê", seria mais importante que "quem" faz a ação, embora este esteja em primeiro lugar na quantidade de ocorrências.

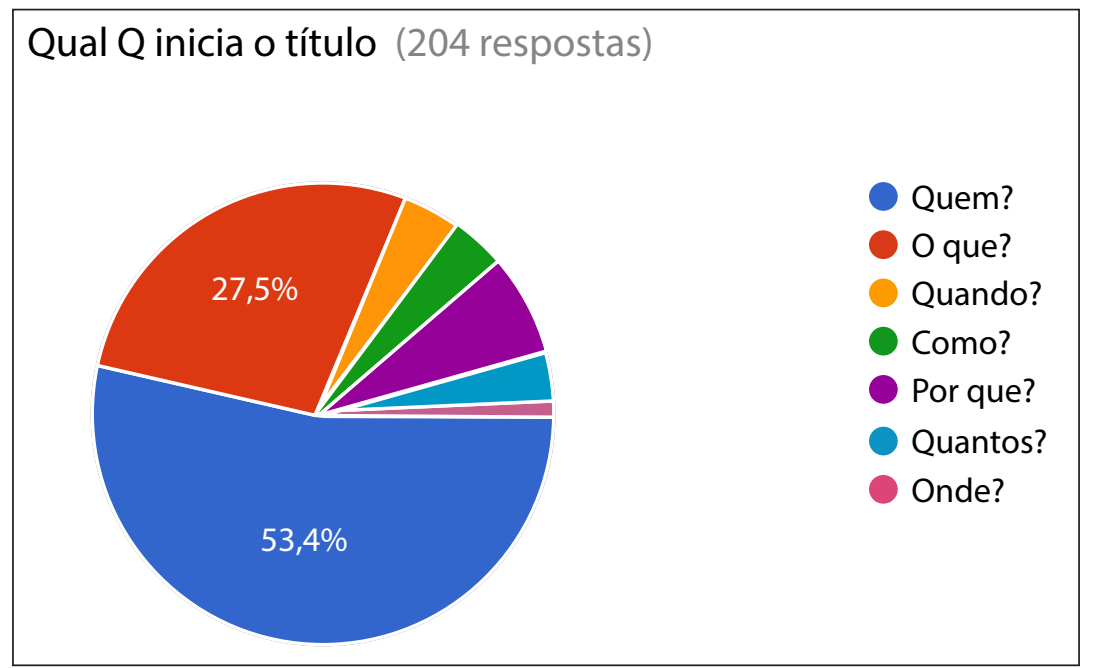

Gráfico 2: Perguntas do lead que iniciam a frase dos títulos Fonte: Elaborado pelos autores (2016)

O "quem", com o qual o sujeito prioritário ratifica a ideia de um título narrativo (sujeito, verbo e complemento), aponta para indícios de um modelo tradicional e pouco criativo e pode lançar questões sobre esse ser, talvez, um resquício de um jornalismo cada vez mais declaratório. Embora isso não possa ser comprovado no estudo até aqui feito, seu resultado assinala para tal questionamento. Outro ponto interessante que se pode observar diz respeito ao número de perguntas 
que são respondidas em cada título. A grande maioria dos títulos publicados preocupou-se em responder três perguntas, que variaram entre si, sendo que "quem" e "o quê" estão em todos os títulos. A variação, desse modo, fica entre as demais perguntas, sendo que "onde" e "quantos" são mais frequentes, por exemplo, que "por quê" ou "como", as quais demandam, em tese, mais espaço para serem explicados. Importante ressaltar, também, que 34\% dos títulos responderam apenas as duas perguntas principais, ou seja, são sucintos na sua construção textual.

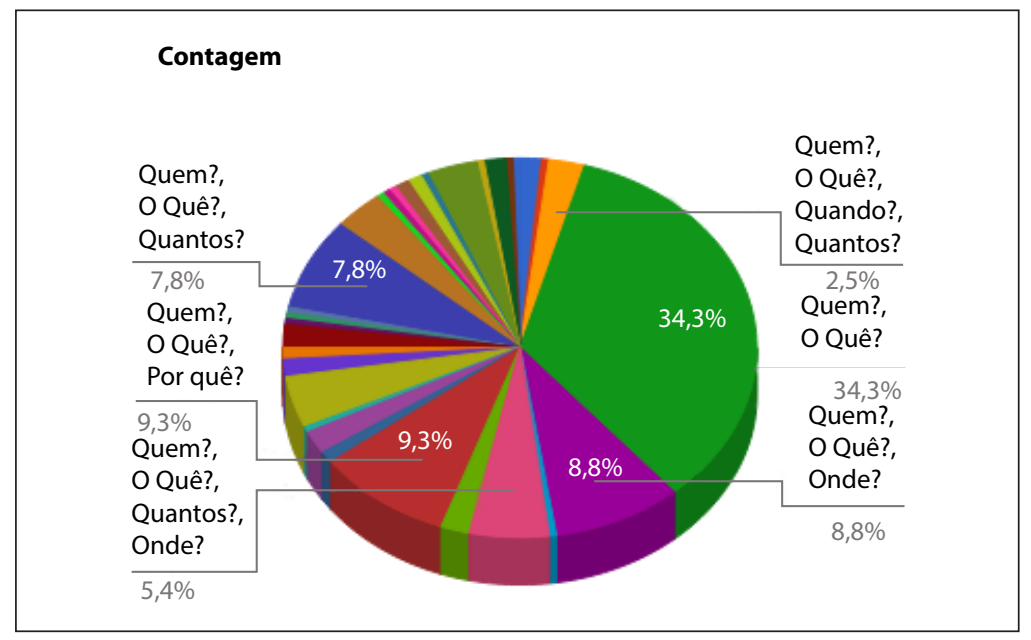

Gráfico 3: Quantas perguntas do lead são respondidas nos títulos

Fonte: Elaborado pelos autores (2016)

O resultado ratifica a ideia de títulos menores e causa preocupação no que tange à inteligibilidade do texto, afinal, responder somente duas perguntas pode gerar mais dúvidas ou, talvez, generalizações. Como diz o manual do Estado, "o título deve em poucas palavras anunciar o fato" (MARTINS FILHO, 1997, p. 283). Pelo jeito, bem poucas. No entanto, a segunda escolha mais comum de usar três respostas, mostra intermediária que aponta para uma preocupação, talvez, de maior esclarecimento na frase do título.

Mais uma questão que intrigava os pesquisadores quanto à prática da construção dos títulos dizia respeito ao uso ou não de pontuação. A pergunta que guiou esse levantamento foi: é permitido algum tipo de pontuação? Se sim, qual 
é comumente usada nos títulos dos veículos? O resultado ratifica a ideia de que, em geral, um bom título não precisa de pontuação, ou seja, consegue ser escrito com uma frase direta e objetiva. Tanto é assim que 54\% dos títulos analisados não tinham nenhum sinal de pontuação e outros 16\% usavam, no máximo, aspas. Nos títulos maiores foi frequente o uso de vírgulas, que apareceram em 33\% dos analisados. Ponto e vírgula e dois-pontos são raros, cada um aparecendo em cerca de $1 \%$ dos títulos. Olhar para esse resultado mostra que os dois-pontos são, de fato, evitados e, como dizem em redações, são uma "muleta" para um editor que não consegue fazer uma frase consistente. Importante notar que as aspas, que aparecem com frequência, não são comumente usadas em frases de fontes, mas sim por regras de manual quanto a nomes de espetáculos ou de outras obras.

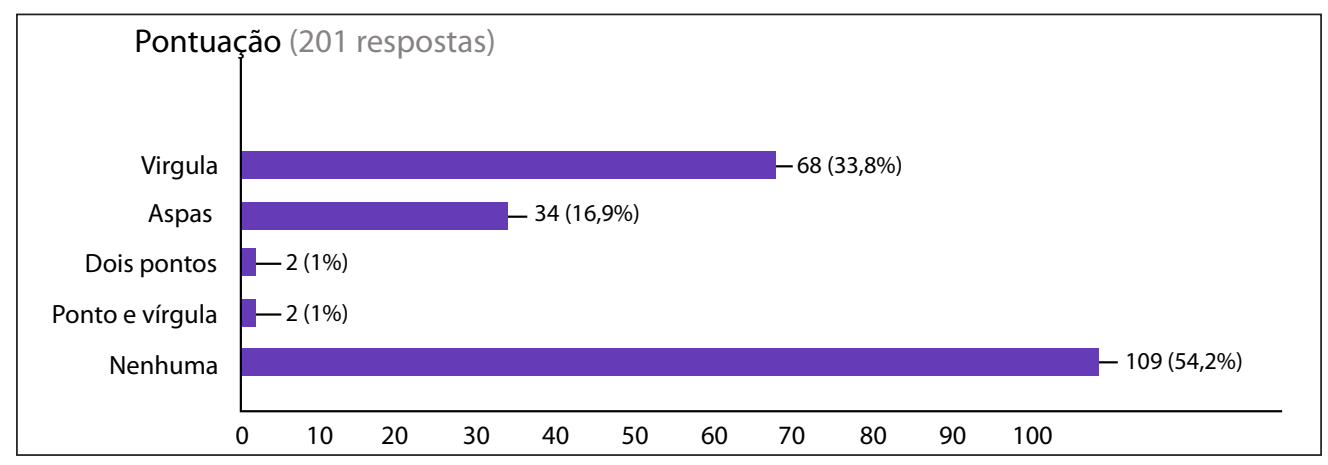

Gráfico 4: Uso dos sinais de pontuação nos títulos Fonte: Elaborado pelos autores (2016)

A ausência de pontuação, além de acompanhar a orientação dos manuais, ajuda na concisão e na objetividade, que são marcas do título na avaliação de autores também. Além da pontuação, o questionamento sobre os títulos atuais inclui a escolha do tempo verbal e da voz usada. Na prática jornalística, de um modo geral, a regra norteadora sempre foi escrever títulos no tempo presente e na voz ativa. Ambos os manuais aqui citados ponderam em verbetes o uso da voz ativa nos títulos. Inclusive o tempo verbal no passado é considerado um tabu na rotina das redações, só podendo ser usado em casos muito raros; assim como o tempo futuro, que afasta o leitor e o distancia do fato, conforme 
apontam autores como Assumpção e Bocchini (2006). O resultado desta pesquisa ratifica as duas orientações: sim, os jornais escrevem na voz ativa e no presente do verbo $(90,2 \%)$; nunca adotam a voz passiva e evitam tempos futuros e passados.

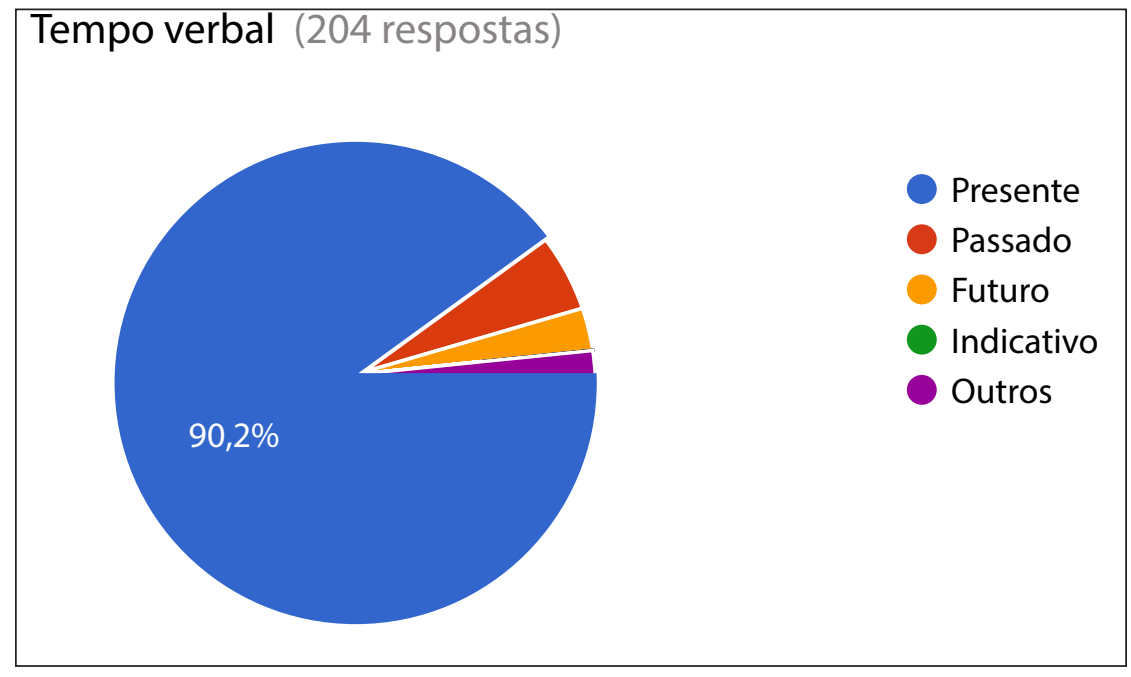

Gráfico 5: Tempos verbais usados nos títulos

Fonte: Elaborado pelos autores (2016)

A escolha do presente afiança aos títulos o sentido de atualidade e mostra que, mesmo com a crise que o imprenso sofre com a concorrência dos sites - que em tese, publicam antes -, o modelo do presente segue forte na construção da narrativa do jornal. Além disso, a voz ativa está explicitada nos manuais como uma regra, e talvez por isso tenha sido encontrada na totalidade dos títulos. A escolha é tradicional no modelo mais profissional de jornalismo e ratifica o modelo de narrativa dos títulos, ainda mais quando a maioria das frases adota o sujeito como a pergunta de abertura a ser respondida. Ou seja, na voz ativa, alguém faz alguma coisa, conta-se uma historinha. Aparentemente, esse é o modelo mais usual.

Outro aspecto muito curioso que o resultado das análises de títulos mostrou diz respeito ao seu tamanho. O estudo detalhou o número de palavras nos 50 primeiros títulos nas quatro categorias: capa do impresso, página interna do impresso; capa do site e página interna do site. O que se pode perceber é que 
os títulos praticados no jornal impresso são pequenos, mais da metade deles têm até seis palavras, sendo que onze destes foram escritos com menos de cinco. E mesmo na página interna, na qual o título é um pouco maior que o manchetado da capa, ainda não chegam a ser muito maiores. No entanto, no ciberjornal o título cresceu muito. Na análise vimos que muito raramente se usam títulos com até seis palavras e nunca vemos frases com menos de cinco delas. Substancialmente os títulos, nesse suporte, têm mais de sete palavras na sua construção.

\begin{tabular}{lcccc}
\hline & Capa impresso & $\begin{array}{c}\text { Interna do } \\
\text { impresso }\end{array}$ & $\begin{array}{c}\text { Capa do } \\
\text { on-line }\end{array}$ & $\begin{array}{c}\text { Interna do } \\
\text { on-line }\end{array}$ \\
\hline Menos de 5 palavras & 11 & 12 & 0 & 1 \\
\hline De 5 a 6 palavras & 15 & 16 & 6 & 4 \\
\hline 7 palavras & 13 & 5 & 10 & 10 \\
\hline Mais de 7 palavras & 11 & 17 & 34 & 35 \\
\hline
\end{tabular}

Tabela 1: Número de palavras nos títulos dos jornais analisados

Fonte: Elaborado pelos autores (2016)

Os dados sobre o número de palavras não atestam uma verdade quanto aos títulos na internet serem maiores, mas são uma pista que pode ser investigada. Talvez aqui se encontre efetivamente a maior mudança do título no futuro. $\mathrm{E}$ então mais palavras devem atrair mais critérios, quem sabe, até para o lead.

\section{Considerações finais}

Considerado um dos elementos mais importantes para a difusão e para a leitura da produção jornalística escrita, os títulos mudam conforme são alteradas as práticas midiáticas. Desde a profissionalização do jornalismo até o momento atual, esses textos mais curtos, mas não menos respeitáveis que o restante das matérias, passaram por transformações que envolvem desde orientação estrutural (tamanho, número de palavras), até seu estilo (mais ou menos objetivo) e semantismo. Na atualidade, embora repitam alguns padrões (tempos e modos verbais, ausência de pontuação), têm repaginado sua composição, principalmente com a ampliação do número de palavras nas edições on-line. O resultado da pesquisa surpreende, já que a maior parte 
das obras sobre o tema tratam de que os títulos devem ser guiados por frases objetivas e curtas. Nesse levantamento vimos que no ciberespaço os jornais costumam aumentar significativamente o seu número de palavras. Aumentar o título significa ter espaço para menos generalizações, mais facilidade de acerto, mas também menos criatividade.

Além de demonstrar estatisticamente e materialmente essa alteração, o estudo permite levantar outros questionamentos, que podem ser aprofundados adiante, sobre o porquê dessa transformação. Talvez estejam ligadas diretamente à estrutura da página na web, que tem mais espaço para a construção textual; ou, quem sabe, à prática apressada do suporte.

Além disso, a pesquisa traz outra contribuição sobre a estrutura dos títulos. A constatação de que os leads e os títulos estão intimamente ligados é antiga, muitos autores já trataram do tema e, como citado nesse artigo, até criaram classificações a partir disso. No entanto, muito desse debate é mais focado na construção do lead que na formatação do título. Assim, ao mostrar essa sistematização, por meio do estudo descritivo dos títulos de dois dos maiores jornais de referência no país, nos permitimos ter um embasamento mais assertivo sobre essa relação. Muito do que se pratica sobre títulos nas redações, e até mesmo como se trata do assunto nas salas de aula, tem uma relação muito próxima com o empirismo, com as experiências de cada jornalista. Nesse trabalho trouxemos essas questões do saber espontâneo para uma constatação científica. Testando esse conhecimento, esta pesquisa ratifica alguns pontos, mas apresenta outros e os coloca de maneira material nesta exposição.

\section{Referências}

AMADEI, R. P. A sobrevivência do jornal impresso diante de novos meios informacionais: padrões textuais e concepções discursivas da Tribuna de Minas. Monografia (Bacharelado em Comunicação Social) - Faculdade de Comunicação Social da Universidade Federal de Juiz de Fora, Juiz de Fora, 2007. 
AMARAL, L. Técnica de jornal e periódico. Rio de Janeiro: Tempo Brasileiro, 1978.

ASSUMPÇÃO, M. E. O.; BOCCHINI, M. O. Recomendações para escrever bem textos fáceis de ler. São Paulo: Manole, 2006.

BAHIA, J. Jornal, história e técnica: as técnicas do jornalismo. São Paulo: Ática, 1990.

BERTOLINI, J. O título da notícia na internet: funções clássicas e impactos na leitura e na compreensão do texto. Ciência em Curso, Palhoça, v. 3, n. 2, p. 99-110, jul./dez. 2014.

BURNETT, L. A língua envergonhada. Rio de Janeiro: Nova Fronteira, 1991.

COMASSETTO, L. R. As razões do título e do lead: uma abordagem cognitiva da estrutura da notícia. Concórdia: UnC, 2003.

CUNHA, D. S. Manchete, títulos e suas formas de expressão: uma pesquisa histórica pelos uivos impressos, idiotas da objetividade e outros modos de ver. Monografia (Graduação em Jornalismo - Habilitação em Jornalismo) - Escola de Comunicação, Universidade Federal do Rio de Janeiro, Rio de Janeiro, 2010.

DOUGLAS, J. Jornalismo: a técnica do título. Rio de Janeiro: Agir, 1966.

GARCIA, L. Manual de redação e estilo. São Paulo: Globo, 2005.

GRADIM, A. Manual de jornalismo. Covilhã: Universidade da Beira Interior, 2000. Disponível em: <https://goo.gl/PKfbA6>. Acesso em: 16 out. 2017. 
GRAY, J.; BOUNEGRU, L.; CHAMBERS, L. (Eds.). Manual de jornalismo de dados. 2015. Disponível em: https://issuu.com/andersonraimello/docs/manual_de_ jornalismo_de_dados_-_lic. Acesso em: 30 out. 2017.

GUIMARÃES, E. A articulação do texto. São Paulo: Ática, 1995.

Manual geral da redação. São Paulo: Folha de São Paulo, 2002.

MEDINA, J. B. Gêneros jornalísticos: uma questão de gênero. In: SIMPÓSIO DA PESQUISA EM COMUNICAÇÃO, 8., 2001a, Vitória. Anais eletrônicos... Disponível em: <https://goo.gl/pkyGgp>. Acesso em: 10 fev. 2017.

. Gêneros jornalísticos: repensando a questão. Symposium, São Paulo, ano 5, n. 1, p. 45-55, jan./jun. 2001b.

MARTINS FILHO, E. L. Manual de redação e estilo. São Paulo: O Estado de S.Paulo, 1997.

MELO, J. M. História do pensamento comunicacional: cenários e personagens. São Paulo: Paulus, 2003.

A opinião no jornalismo brasileiro. Petrópolis: Vozes, 1985.

MESSA, F. C. Jornalismo esportivo não é só entretenimento. In: FÓRUM NACIONAL DE PROFESSORES DE JORNALISMO, 8., 2005, Maceió. Anais... Maceió: FNPJ, 2005. p. 1-8. Disponível em: <https://goo.gl/skDEHF>. Acesso em: 16 out. 2017. 
MOUILLAUD, M. O título e os títulos. In: MOUILLAUD, M.; PORTO, S. D. (Org.). O jornal: da forma ao sentido. Brasília, DF: UnB, 2002. p. 99-116.

PELLIM, T. Análise textual de títulos jornalísticos: um estudo comparativo entre as seções de ciência e esporte. Vertentes, São João del-Rei, v. 34, p 171-178, 2009. Disponível em: <https://goo.gl/p8K6dQ>. Acesso em: 16 out. 2017.

RODRIGUES, A. D. Estratégias da comunicação. Lisboa: Presença, 1997.

ROSSI, C. O que é jornalismo. São Paulo: Brasiliense, 1981.

SARTORI, R. A relevância da inferência relevante. Dissertação (Mestrado em Linguística e Letras) - Faculdade de Letras da Pontifícia Universidade Católica do Rio Grande do Sul, Porto Alegre, 1999.

TÍTULO. In: NOVO manual da redação. São Paulo: Folha da Manhã, 1996. Disponível em: <https://goo.gl/RTTK6E>. Acesso em: 18 out. 2017.

VIZEU, A.; MAZZAROLO, J. Telejornalismo: onde está o lead? Famecos, Porto Alegre, v. 6, n. 11, p. 57-63, dez. 1999.

submetido em: 09 mar. 2017 | aprovado em: 23 jun. 2017 